\title{
Interleukin 6 Gene Expression in Normal and Neoplastic B Cells
}

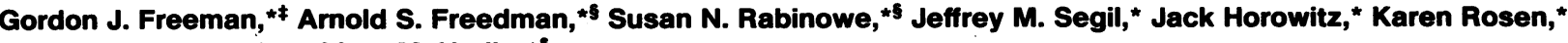 \\ James F. Whitman, " and Lee M. Nadler*s \\ ${ }^{*}$ Division of Tumor Immunology, Dana-Farber Cancer Institute, and the Departments of ${ }^{\ddagger}$ Pathology and ${ }^{\S}$ Medicine, Harvard Medical
}

School, Division of Tumor Immunology, Dana-Farber Cancer Institute, Boston, Massachusetts 02115

\begin{abstract}
In the present report we demonstrate that the IL-6 gene is expressed in anti-Ig-activated and neoplastic B cells. After activation with anti-Ig, splenic B cells rapidly expressed IL-6 mRNA with peak expression occurring at $4 \mathrm{~h}$ and declining rapidly thereafter. In an attempt to exclude that the IL-6 mRNA expression was in non-B cells, $T$ cells and monocytes were extensively depleted. In this highly purified B cell population, IL-6 mRNA was retained, whereas the expression of the T cell- and monocyte-restricted CD2 and CD14 genes was nearly undetectable. These results are consistent with the conclusion that activated B cells express IL-6 mRNA. Because we found IL-6 mRNA expression in normal activated B lymphocytes, we examined the expression of IL-6 mRNA in B cell neoplasms. 11 of 25 non-Hodgkins $B$ cell lymphomas and 4 of 4 myelomas and plasma cell leukemias expressed IL-6 mRNA, whereas only 1 of 19 B cell leukemias was positive. To exclude that IL-6 mRNA expression in neoplastic B cells was the result of contaminating non-B cells, $T$ cells and monocytes were extensively depleted from the tumor specimens. In the three IL-6-positive tumor samples depleted of $T$ cells and monocytes, IL-6 mRNA expression was retained in all cases. These observations provide support for the idea that the IL-6 gene is expressed in normal activated and neoplastic $B$ cells.
\end{abstract}

\section{Introduction}

A number of soluble factors have been shown to regulate the growth and differentiation of murine and human B lymphocytes. Recently, several of these factors have been molecularly and functionally characterized and their genes have been cloned (1-5). Functional studies using recombinant factors demonstrate that individual cytokines can activate resting B cells $(6)$, induce proliferation of activated B cells $(5,7)$, regulate isotype expression (8), or induce Ig secretion (9).

One of these cytokines, termed IL-6, was shown to be one of the major factors necessary for the terminal differentiation of activated B cells into Ig-secreting cells (9). IL-6 was first identified in the culture supernatant of PHA-stimulated PBL (10). Although initially isolated from a transformed T cell line (11), increasing evidence demonstrated that IL-6 is also se-

Address correspondence to Dr. Gordon Freeman, Department of Tumor Immunology, Dana-Farber Cancer Institute, 44 Binney Street, Boston, MA 02115.

Received for publication 7 September 1988 and in revised form 30 November 1988.

J. Clin. Invest.

(C) The American Society for Clinical Investigation, Inc.

0021-9738/89/05/1512/07 \$2.00

Volume 83, May 1989, 1512-1518 creted by other cell types (12-14). Within the hematopoietic system, monocytes appear to be the major producer (14). Moreover, recent studies demonstrate that fibroblasts, endothelial cells, and some epithelial tumors have the capacity to secrete IL-6. In addition to its ability to induce activated B cells to secrete Ig, human IL-6 has been shown to induce the growth of murine plasmacytomas (15), hybridomas (14), and EBVinfected human B lymphocytes (16). Although initially thought to be a B cell-restricted cytokine, it has become increasingly clear that IL-6 has a multitude of additional effects on hematopoietic and nonhematopoietic cells. To date, these include antiviral activity (12) (cloned as IFN $\beta 2$ ), granulocyte/ macrophage CSA (17), cytotoxic T cell differentiation activity (18), and induction of acute phase protein expression by the liver (19). IL-6 also has several IL-1-like activities that include costimulation of thymocyte proliferation (20), activation of T lymphocytes (21), and induction of fever.

In addition to its production by normal cells, preliminary evidence suggested that IL- 6 could also be produced by neoplastic cells. Hirano et al. initially demonstrated that some cardiac myxomas produce IL-6, and suggested that many of the autoimmune characteristics of this disease might be secondary to IL-6 secretion (4). Recently, Kawano and his colleagues have demonstrated that IL- 6 is produced by human myelomas (22). These tumors appear to proliferate in response to IL-6; moreover, this proliferation is specifically inhibited by antibodies directed against IL-6. The production of IL- 6 by myelomas suggests that IL- 6 is involved in the growth of these terminally differentiated neoplastic $B$ cells.

Malignant transformation leading to unrestricted cell growth may occur when a cell acquires the ability to produce and respond to endogenous factors via cell surface or intracytoplasmic receptors. This process has been termed autocrine stimulation (23). The evidence that IL-6 is important in the differentiation of activated B lymphocytes and in the growth of myelomas suggests that IL-6 might function as a growth factor for neoplastic B cells. To address this question, we have examined whether the IL- 6 gene is expressed in a variety of B cell tumors and after activation of resting $B$ lymphocytes in vitro. In the studies to be reported below, we demonstrate that antiIg-activated B cells and B cell neoplasms that correspond to mid- to later stages of differentiation appear to express this gene.

\section{Methods}

Adult human tissues. Normal spleen was obtained from operative specimens of patients not known to have any systemic or malignant disease, according to appropriate Human Protections Committee validation and informed consent. Single cell suspensions of spleen tissue were prepared by dissolution in HBSS with forceps and scissors and extrusion through a stainless steel mesh. Mononuclear cells, isolated by Ficoll-Hypaque density gradient centrifugation, were enriched for B cells by E-rosetting to deplete $T$ cells. Cells were either used fresh or 
cryopreserved in $10 \%$ DMSO and $20 \%$ FCS at $-196^{\circ} \mathrm{C}$ in the vapor phase of liquid nitrogen until the time of study. Cells were recovered at viabilities of $70-90 \%$.

Patients' samples. Tumor cells were obtained from untreated patients with non-Hodgkin's lymphoma (NHL) ${ }^{1}$ after appropriate Human Protection Committee validation and informed consent. Samples contained $>75 \%$ neoplastic cells by Wright-Giemsa stain morphology and were classified according to a modified Rappaport system (24). However, nodular lymphoma samples generally had $<75 \%$ neoplastic cells and myeloma samples had $20-40 \%$ neoplastic cells. Plasma cell leukemia samples had $>95 \%$ neoplastic cells. Tumor specimens were prepared similarly to normal spleen but were not E-rosetted, and were studied either fresh or after cryopreservation. B cell lineage was established by the presence of monoclonal surface Ig and/ or the pan B cell antigen B1 (CD20) as determined by indirect immunofluorescence with the use of anti-kappa, -lambda, - IgG, - IgM, and -B1 MAbs (25).

In vitro stimulation. Splenic B cells were activated by incubation with anti-Ig coupled beads as described (25).

Immunomagnetic depletion of T cells and monocytes. Splenic sheep erythrocyte receptor negative $(\mathrm{E}-)$ cells or tumor cell suspensions were incubated with anti-T cell and anti-monocyte MAb T4 (CD4), T8 (CD8), My8 (CD1 lb), and My4 (CD14). MAbs were used as ascites at saturating binding conditions. Cells were incubated for $30 \mathrm{~min}$ at $4^{\circ} \mathrm{C}$ and washed twice. Immunomagnetic beads in the form of affinity-purified sheep anti-mouse IgG coupled to monodisperse magnetizable polymer particles (Dynabeads M-450, prod. no. 11002; Dynal, Oslo, Norway) were added at a bead to cell ratio of $8: 1$. The suspension was mixed gently for $30 \mathrm{~min}$ at $4^{\circ} \mathrm{C}$ and cells binding beads were removed by the application of a magnetic field.

RNA isolation. RNA was isolated by the guanidine thiocyanate-cesium chloride density gradient centrifugation procedure of Chirgwin et al. (26). After centrifugation of the RNA through cesium chloride, the supernatant was aspirated and the bottom $0.5 \mathrm{~cm}$ of the tube, containing the clear RNA pellet, was excised with a razor blade. Pellets were dissolved thoroughly in $10 \mathrm{mM}$ Tris- $\mathrm{HCl}, \mathrm{pH} 7.5,1 \mathrm{mM}$ EDTA, $5 \%$ sarkosyl, $5 \%$ phenol, adjusted to $0.4 \mathrm{M} \mathrm{NaCl}$, and extracted with $2 \mathrm{vol}$ of phenol/chloroform/isoamyl alcohol, 50:49:1 (vol/vol/vol). RNA was ethanol precipitated twice and the concentration determined by the $O D$ at $260 \mathrm{~nm}$.

RNA blot analysis. RNA ( $15 \mu \mathrm{g}$ whole cell RNA) was electrophoresed in $1.2 \%$ agarose/formaldehyde gels (27) and blotted onto nitro cellulose filters (NitroPlus; Micron Separations, Inc., Westborough, MA). The integrity and amount of each RNA was assessed by staining the gel with ethidium bromide. Hybridization was in $50 \%$ formamide, $0.75 \mathrm{M} \mathrm{NaCl}, 0.15 \mathrm{M}$ Tris-HCl (pH 8), $5 \mathrm{mM}$ EDTA, $0.1 \mathrm{M} \mathrm{NaPO}_{4}$, (pH 7), $0.1 \%$ Na pyrophosphate, $0.1 \%$ SDS, $1 \times$ Denhardt's, $50 \mu \mathrm{g} / \mathrm{m}$ salmon sperm DNA, and $10 \%$ dextran sulfate at $42^{\circ} \mathrm{C}$ for $24 \mathrm{~h}$. Blots were washed in three changes of $15 \mathrm{mM} \mathrm{NaCl}, 0.1 \mathrm{mM}$ EDTA, $2 \mathrm{mM}$ Tris (pH 8), $0.1 \%$ Na pyrophosphate, $10 \mathrm{mM} \mathrm{NaPO}_{4}(\mathrm{pH} 7)$, and $0.1 \%$ SDS for $20 \mathrm{~min}$ at $60^{\circ} \mathrm{C}$. Specific hybridization signals were visualized by autoradiography using film with intensifying screens (XAR-5; Eastman Kodak Co., Rochester, NY). For rehybridizations, blots were stripped of ${ }^{32} \mathrm{P}$-labeled probe by incubation at $100^{\circ} \mathrm{C}$ for $1.5 \mathrm{~min}$ in 10 $\mathrm{mM} \mathrm{NaPO}_{4}(\mathrm{pH} 7), 0.1 \%$ SDS.

Probe preparation. Probes were purified for hybridization by restriction enzyme digestion and two cycles of agarose gel electrophoresis to remove vector sequences. DNA was eluted from agarose by the $\mathrm{NaI} /$ glass powder method (28) and labeled by random oligonucleotide

1. Abbreviations used in this paper: ALL, B acute lymphocytic leukemia; Burkitt's, Burkitt's lymphoma; CLL, chronic lymphocytic leukemia; DLCL, diffuse large cell lymphoma; DPDL, diffuse poorly differentiated lymphoma; E-, sheep erythrocyte receptor negative; HCL, hairy cell leukemia; NHL, non-Hodgkin's lymphoma; NPDL, nodular poorly differentiated lymphoma; PCL, plasma cell leukemia; ProLL, prolymphocytic leukemia. priming using $\alpha-{ }^{32} \mathrm{P}$-labeled deoxyribonucleotides and Klenow fragment of DNA polymerase I (29).

DNA probes. A full-length cDNA encoding IL-6 was isolated by oligonucleotide hybridization (nucleotides 330-357 of reference 4) of an activated PBL cDNA library in the eukaryotic expression vector, $\mathrm{pcD}$ (30). The identity of the clone was confirmed by restriction enzyme digest, partial sequencing, and bioassay. After transfection of IL-6 cDNA-pcD DNA into cos cells, the supernatant was harvested at $72 \mathrm{~h}$ and assayed for stimulation of Ig production by anti-Ig activated B cells.

When the full-length IL-6 cDNA insert was used as a probe in Northern blot analyses of total cellular RNA, cross-hybridization was seen to 18s rRNA as well as to the authentic 1,300-nucleotide IL-6 mRNA. This result was also seen using a full-length IL-6 cDNA kindly provided by Steve Clark of the Genetics Institute (Cambridge, MA). A probe consisting of the Ban II-Xho I fragment (nucleotides 657-3' end of reference 4) did not show this cross-hybridization to 18s rRNA and was used thereafter.

Full-length cDNA clones encoding CD14 (My4) and CD2 (T11) were generously provided by David Simmons and Brian Seed (Massachusetts General Hospital, Boston, MA). Probes for c-myc and IL-2R were generously provided by Robert Gallo (National Cancer Institute, Bethesda, MD) and Warner Greene (Duke University Medical Center, Durham, NC), respectively.

\section{Results}

IL-6 gene expression after B cell activation. After activation of splenic $\mathrm{E}-$ cells ( $>80 \% \mathrm{CD} 20+$ ) for various times with anti-Ig, total cellular RNA was extracted and expression of IL-6, IL-2R, and c-myc mRNAs was determined by Northern blot analysis. Steady-state levels of gene expression were examined by loading equal amounts $(15 \mu \mathrm{g})$ of total cellular RNA prepared at distinct times points after activation. Fig. 1 dem. 'nstrates that equal amounts of RNA were studied, as evidenced by the equal staining intensity of the ribosomal RNAs with ethidium bromide.

The level of IL- 6 mRNA was extremely low in unstimulated B cells (Fig. 1). After activation with anti-Ig, IL-6 mRNA was rapidly induced with 1.3- and 2.3-fold increases observed at 10 and $30 \mathrm{~min}$, respectively. Initially, two closely spaced bands ( 1.3 and $1.4 \mathrm{~kb}$ ) could be discerned. By $4 \mathrm{~h}$, expression was maximal (21.4-fold increase), with only an intense $1.3-\mathrm{kb}$ band observed. Expression declined rapidly after $8 \mathrm{~h}$, with minimal mRNA being detected at $24 \mathrm{~h}$ (0.7-fold) and none detected thereafter. When protein synthesis was blocked with cycloheximide, an additional 3.2-fold increase in IL-6 mRNA expression at $8 \mathrm{~h}$ was seen. Similar data was observed for cells from three different spleens and a representative experiment is shown in Fig. 1.

Because splenic $\mathrm{E}-$ cells are contaminated with $<5 \% \mathrm{~T}$ cells and $<10 \%$ monocytes, it was important to demonstrate that the IL-6 mRNA detected after anti-Ig stimulation was derived from $B$ cells and not a contaminating cell population. Splenic E- cells were activated with anti-Ig and after $8 \mathrm{~h}$, the cells were treated with MAbs specific for T cells (CD4 and CD8) and monocytes (CD1 $1 \mathrm{~b}$ and CD14). Contaminating T cells and monocytes expressing these antigens were then removed by the addition of sheep anti-mouse Ig coupled to magnetic beads. After depletion of non-B cells, RNA was prepared, Northern blotted, and probed with an IL-6 probe. Fig. 2 (left) demonstrates that the level of IL-6 mRNA expression in highly purified, activated B cells was not altered by the removal of $T$ cells and monocytes. The extent of monocyte depletion was assessed by rehybridizing the blot with a probe for 

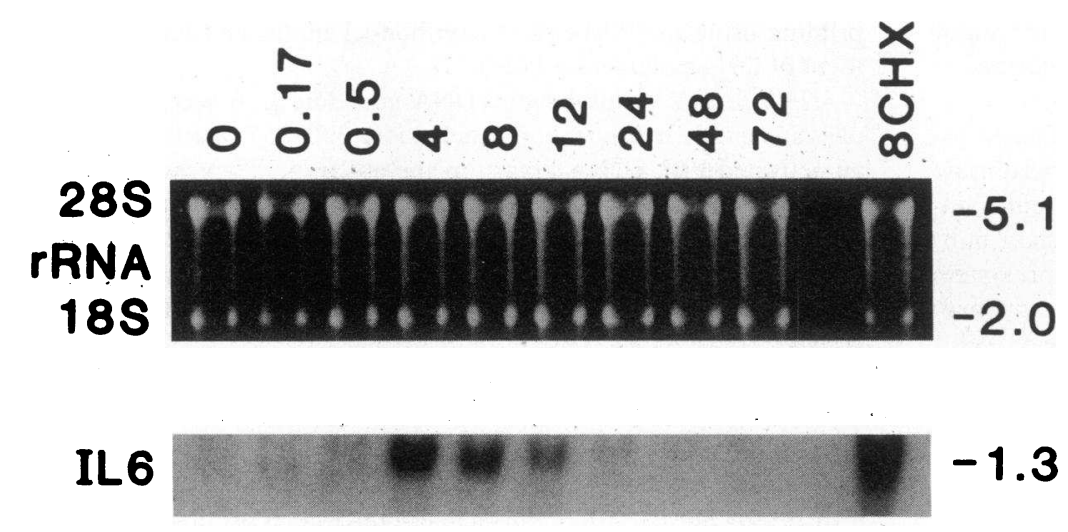

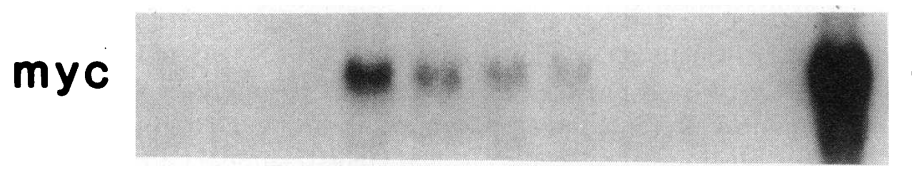

$-2.3$

IL2R

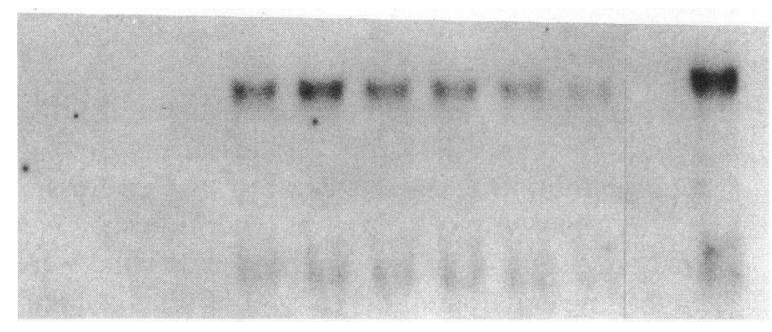

$-3.5$

$-1.5$
Figure 1. IL-6 mRNA expression after activation of normal B cells. Splenic E- cells were activated with anti-Ig coupled beads and cells were harvested at the indicated hours thereafter. $8 \mathrm{CHX}$ indicates that cells were activated in the presence of $10 \mu \mathrm{g} / \mathrm{ml}$ cycloheximide and harvested at $8 \mathrm{~h}$. RNA was isolated and 15 $\mu \mathrm{g}$ of total cellular RNA was fractionated on agarose gels, transferred to nitrocellulose, and hybridized sequentially with ${ }^{32} \mathrm{P}$-labeled probes for $\mathrm{IL}-6, \mathrm{c}-m y c$, and IL-2R (p55) as indicated. The RNA size (in kilobases) is indicated at the right. Before transfer, the gel was stained with ethidium bromide and photographed. The top panel shows that equal amounts of RNA were loaded on each lane. A darker autoradiogram was used for scanning early time points. the monocyte-specific gene, CD14 (My4). Fig. 2 (middle) shows that the splenic E- population was contaminated with $\mathrm{CD} 14+$ cells, but that these cells were reduced to undetectable levels by immunomagnetic depletion. The blot was also rehybridized with the $\mathrm{T}$ cell-specific probe, CD2 (T11). Fig. 2 (right) shows that the level of $\mathrm{CD} 2+$ cells is greatly reduced
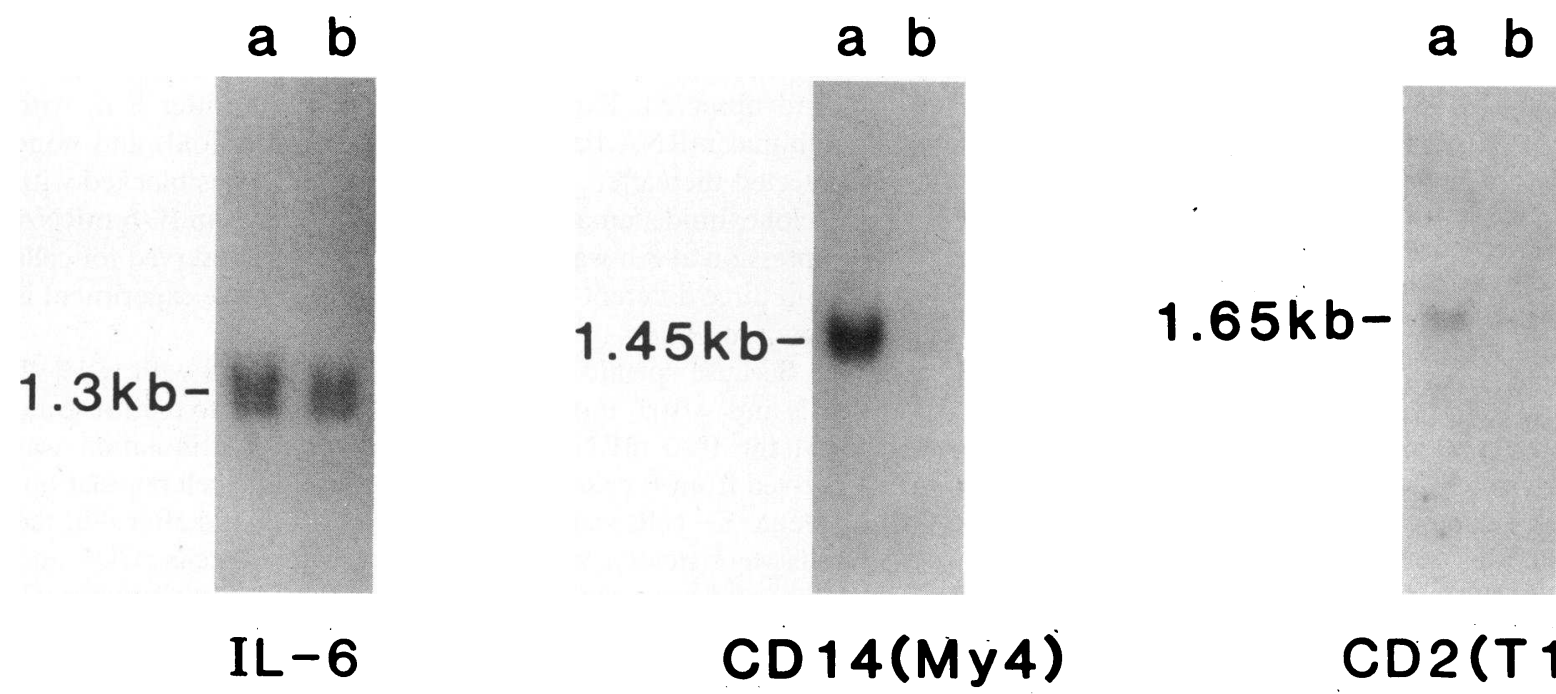

Figure 2. Anti-Ig activation induces IL-6 mRNA expression in activated B cells but not in contaminating T cells or monocytes. Splenic E- cells were activated with anti-Ig coupled beads and harvested after $4 \mathrm{~h}$. The sample was divided in two and RNA was prepared from one aliquot (lane $a$ ). The other aliquot was treated with a cocktail of anti-T cell and anti-monocyte antibodies. Cells expressing these antigens were removed by the addition of sheep anti-mouse Ig coupled to magnetic beads, followed by the application of a magnetic field. RNA was prepared from the purified B cells (lane $b$ ). $15 \mu \mathrm{g}$ of total cellular RNA was fractionated on an agarose gel, transferred to nitrocellulose, and hybridized sequentially with ${ }^{32} \mathrm{P}$-labeled probes for IL-6, CD14, and CD2 as indicated. RNA size (in kilobases) is indicated to the left. 
after depletion of $\mathrm{T}$ cells and monocytes. These studies support the idea that IL- 6 is produced by activated B cells.

Because IL- 6 was expressed very rapidly after B cell activation, it was of interest to compare the kinetics of IL-6 mRNA expression with that of other genes expressed after B cell activation. The proto-oncogene c-myc and the IL-2R gene were examined for expression after in vitro activation of unstimulated B cells with anti-Ig (Fig. 1). The level of c-myc expression was extremely low in the unstimulated splenic E-population. After activation, c-myc mRNA levels increased threefold within the period between 10 and $30 \mathrm{~min}$. At $4 \mathrm{~h}$ after activation the level of c-myc expression had increased 153-fold, as compared with the unstimulated population. After $4 \mathrm{~h}$ the level of c-myc mRNA declined rapidly, reaching low levels by $48 \mathrm{~h}$. Cycloheximide treatment led to an additional 12-fold increase in the levels of c-myc mRNA at $8 \mathrm{~h}$. Like c-myc mRNA, the level of IL-2R mRNA was extremely low in unstimulated splenic E- cells and demonstrated no increase within the first $30 \mathrm{~min}$ after activation with anti-Ig. However, by $4 \mathrm{~h}$ the level had increased 40 -fold. The maximal expression was seen at $8 \mathrm{~h}$ with both the 1.5- and 3.5-kb mRNAs expressed and peaking with a 78-fold increase. The IL-2R 3.5-kb mRNA was 3-4-fold more intense than the $1.5-\mathrm{kb}$ mRNA band. In activated $\mathrm{T}$ cells the $1.5-\mathrm{kb}$ mRNA is usually more intense (31). In contrast to IL-6 and c-myc, the decrease in IL-2R mRNA was gradual and was still $\sim 25 \%$ of maximal levels at $72 \mathrm{~h}$. Cycloheximide treatment led to an additional 2.4-fold increase in the level of IL-2-R mRNA at $8 \mathrm{~h}$.

IL-6 $m R N A$ expression in neoplastic $B$ cells. Previous studies have suggested that neoplastic B cells correspond to subpopulations of $B$ cells at distinct stages of differentiation due to their cell surface expression of B cell restricted and associated activation antigens. It was, therefore, of interest to determine whether subgroups of B cell tumors also expressed IL-6 mRNA. To examine IL-6 expression in malignant B cells, RNA was prepared from a representative panel of B cell malignancies, including tumors corresponding to early, middle, and late stages of normal B cell ontogeny. Most specimens were $75 \%$ replaced by tumor cells except for the myeloma specimens, which were $20-50 \%$ replaced. Total cellular RNA was Northern blotted and hybridized with a probe specific for the IL- 6 gene. The results are shown in Figs. 3 and 4 and summarized in Table I.

Northern blot analysis demonstrated that the IL-6 gene is expressed in some B cell malignancies and that the expression appears to cluster in several histologically defined subgroups. Whereas only 1 of 19 leukemias (B acute lymphocytic leukemia [ALL], chronic lymphocytic leukemia [CLL], hairy cell leukemia [HCL], and prolymphocytic leukemia [ProLL]) demonstrated IL- 6 mRNA expression, 11 of 25 B cell lymphomas and 4 of 4 myelomas expressed the gene. Of the lymphomas (nodular poorly differentiated lymphoma [NPDL], diffuse large cell lymphoma [DLCL], diffuse poorly differentiated lymphoma [DPDL], and Burkitt's lymphoma [Burkitt's]) $\sim 50 \%$ expressed IL-6 mRNA. Moreover, all of the plasmacytoid tumors (myeloma and plasma cell leukemia [PCL]) expressed the gene. In addition to the usual 1.3-kb mRNA, some plasmacytoid tumors expressed a 2.8-kb mRNA that hybridized to the IL- 6 probe. This larger transcript might reflect the use of a downstream polyadenylation site or alternative splicing. We do not yet know if the protein encoded by the 2.8-kb mRNA is identical to that of the 1.3-kb mRNA.

Since IL-6 is now known to be synthesized by a variety of cell types including monocytes, $\mathrm{T}$ cells, and endothelial cells, it
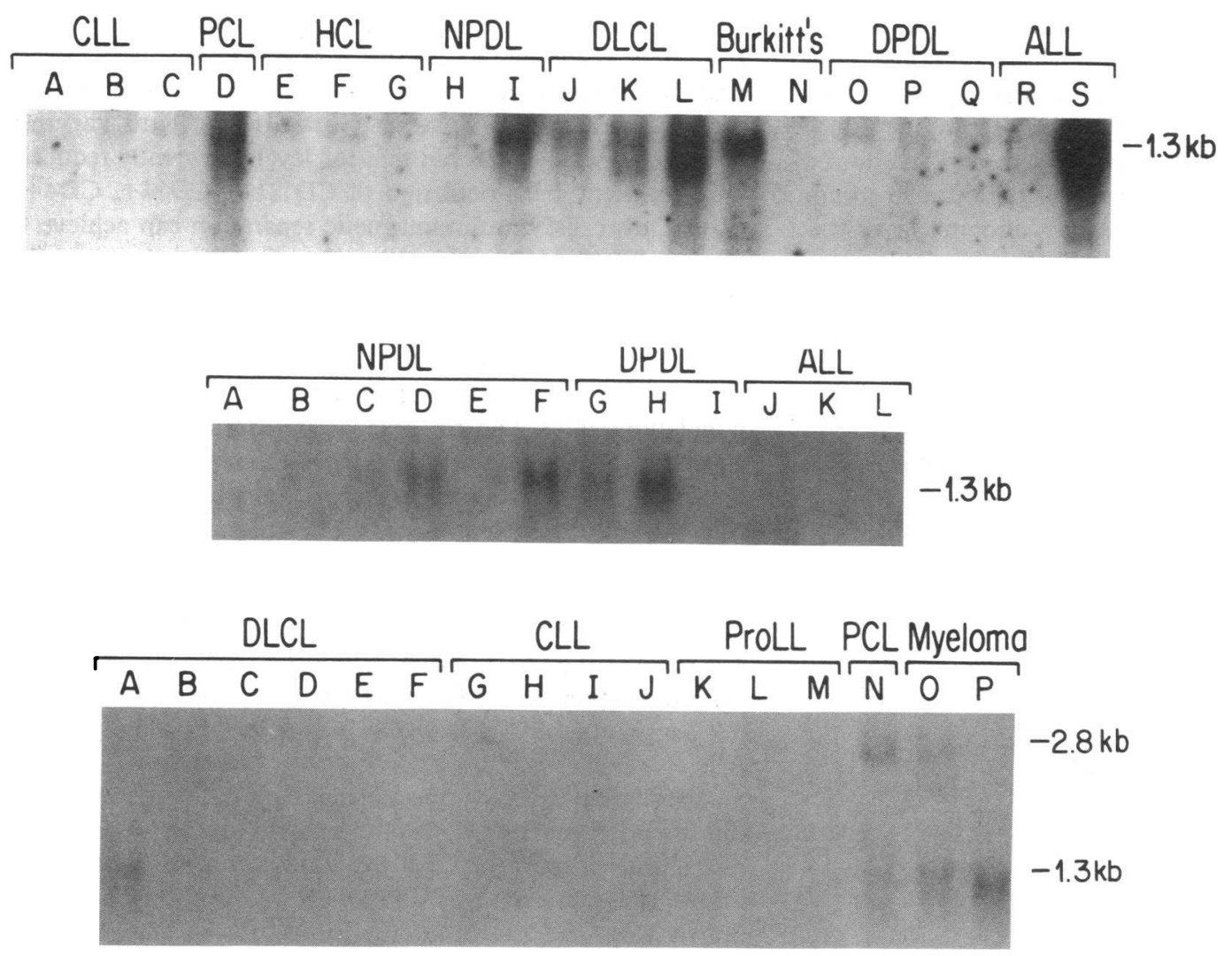
Figure 3. Northern blot analysis of IL-6 mRNA in B cell malignancies. 15 $\mu \mathrm{g}$ of total cellular RNA was isolated and fraction- ated on agarose gels, transferred to nitrocellu- lose, and hybridized with a ${ }^{32}$ P-labeled IL-6 cDNA probe. Lanes contain RNA from B cell malig- nancies as indicated: CLL, PCL, HCL, NPDL, DLCL, Burkitt's, DPDL, ALL, ProLL, and my- eloma.




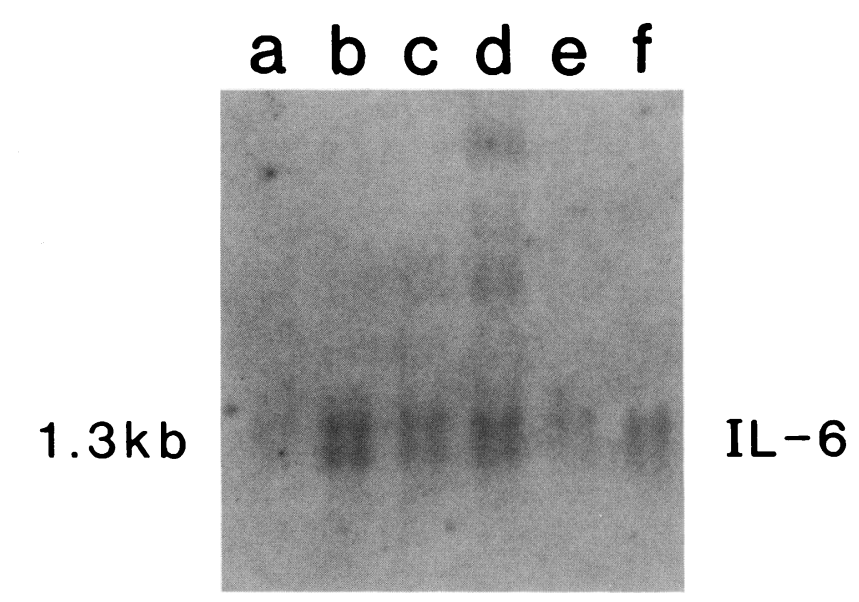

$1.45 \mathrm{~kb}$

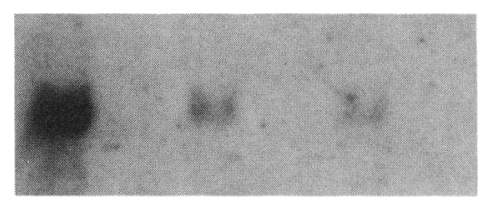

CD 14(My4)

$1.65 \mathrm{~kb}$

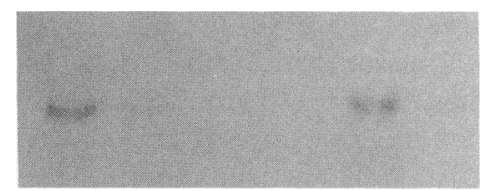

Figure 4. Northern blot analysis of IL-6 mRNA in $B$ cell malignancies before and after depletion of $T$ cells and monocytes. $T$ cells and monocytes were depleted from tumor samples by treatment with a cocktail of anti-T cell and anti-monocyte MAbs. Cells expressing these antigens were removed by the addition of sheep anti-mouse Ig coupled to magnetic beads followed by the application of a magnetic field. Total cellular RNA was prepared before (lanes $a, c$, and $e$ ) and after (lanes $b, d$, and $f$ ) $\mathrm{T}$ cell and monocyte depletion, fractionated on an agarose gel, transferred to nitrocellulose, and hybridized with ${ }^{32} \mathrm{P}$-labeled probes for IL-6, CD14, and CD2. RNA was prepared from a DLCL (lanes $a$ and $b$ ), a DLCL (lanes $c$ and $d$ ), and a NPDL (lanes $e$ and $f$ ). was important to demonstrate, as was shown for activated B cells, that the IL- 6 mRNA seen in B cell malignancies is indeed expressed by the tumor cells. Representative tumor samples were incubated with anti-T cell and anti-monocyte MAbs. Contaminating $\mathrm{T}$ cells and monocytes expressing these antigens were then removed by the addition of sheep anti-mouse Ig coupled to magnetic beads. After purification of the tumor cells, RNA was prepared, Northern blotted, and hybridized with an IL-6 probe (Fig. 4, top). Each of the purified tumor samples retained IL-6 gene expression and the level was

Table I. Expression of IL-6 mRNA by B Cell Neoplasms

\begin{tabular}{|c|c|c|}
\hline Neoplasm & $\begin{array}{l}\text { Number expressing } \\
\text { IL-6 mRNA* }\end{array}$ & $n$ \\
\hline \multicolumn{3}{|l|}{ Leukemias } \\
\hline ALL & 1 & 5 \\
\hline CLL & 0 & 8 \\
\hline ProLL & 0 & 3 \\
\hline HCL & 0 & 3 \\
\hline \multicolumn{3}{|l|}{ Lymphoma } \\
\hline NPDL & 4 & 8 \\
\hline DLCL & 4 & 9 \\
\hline DPDL & 2 & 6 \\
\hline Burkitt’s & 1 & 2 \\
\hline \multicolumn{3}{|c|}{ Plasma cell tumors } \\
\hline Myeloma ${ }^{\ddagger}$ & 4 & 4 \\
\hline
\end{tabular}

* Data from Figs. 3 and 4.

‡ Including PCL. slightly higher after monocyte and $\mathrm{T}$ cell depletion. Northern blot analysis with a CD14 probe showed that the unpurified tumor cells were contaminated with varying amounts of CD14+ monocytes but that none could be detected after magnetic bead depletion of CD11b+, CD14+, CD4+, and CD8+ cells. Northern blot analysis with $\mathrm{CD} 2$ probe showed that the unpurified tumor cells were contaminated with varying amounts of $\mathrm{CD} 2+$ cells but that the level was greatly reduced after magnetic bead depletion of $\mathrm{CD} 11 \mathrm{~b}+, \mathrm{CD} 14+, \mathrm{CD} 4+$, and CD8+ cells. Immunomagnetic separation can achieve 5 logs of depletion (32) and has the advantage that all manipulations are at $4^{\circ} \mathrm{C}$, thus preventing cellular interactions before separation. Before purification, the two DLCLs examined had 72 and 95\% CD20+ cells and the NPDL had 64\% CD20+ cells. After immunomagnetic depletion, both the tumor cell populations and the normal splenic cell populations had $<1 \%$ CD4+ or CD14+ cells as judged by cell sorter analysis. Northern blot analysis using cell type-specific, relatively abundant mRNAs is an alternative way to assess cell purity and is $\sim 10-$ fold more sensitive than cell sorter analysis. Although all myelomas appear to express IL-6 mRNA, we have not purified myeloma cell populations to homogeneity and therefore cannot exclude the contribution of normal marrow cells. However, the expression of IL-6 mRNA by the PCL (99\% tumor cells) supports the idea that IL-6 is expressed by the myeloma cells.

In addition to tumor cells isolated from patients, long-term cell lines derived from B, T, and myeloid tumors were examined. In contrast to the freshly explanted tumors, most longterm B cell lines examined did not express the IL-6 gene (data not shown). These included the Burkitt's lines Raji, Ramos, 
Daudi, and Namalwa, and the IL-6-responsive, lymphoblastoid line, CESS. Of five myeloma cell lines tested, only U266 was positive, whereas the HS-Sultan, IM-9, RPMI 8226, and ARH 77 myeloma lines were negative. The K562 erythroleukemia and the Rex $\mathrm{T}$ cell leukemia lines were also negative.

\section{Discussion}

In the present report we demonstrate that the IL-6 gene is expressed in anti-Ig activated and neoplastic B cells. After activation with anti-Ig, splenic E- cells rapidly expressed IL-6 mRNA with peak expression occurring at $4 \mathrm{~h}$ and declining rapidly thereafter. In an attempt to exclude that the IL-6 mRNA expression was in non-B cells, we extensively depleted $T$ cells and monocytes. In this highly purified population, IL-6 mRNA was retained, whereas the expression of the $T$ cell- and monocyte-restricted CD2 and CD14 genes were nearly undetectable. These results are consistent with the conclusion that activated B cells express IL- 6 mRNA. Because we found IL- 6 mRNA expression in normal activated $B$ lymphocytes, we examined the expression of IL- 6 mRNA in B cell neoplasms. 11 of 25 B cell NHL and 4 of 4 myelomas, expressed IL- 6 mRNA, whereas only 1 of $19 \mathrm{~B}$ cell leukemias were positive. To exclude that IL- 6 mRNA expression in neoplastic B cells was the result of contaminating non-B cells, we extensively depleted $T$ cells and monocytes from the tumor specimens. In the three IL- 6 positive tumor samples depleted of $T$ cells and monocytes, IL- 6 mRNA expression was retained in all cases. These observations provide support for the idea that the IL- 6 gene is expressed in normal activated and neoplastic B cells.

The synthesis of IL- 6 mRNA by anti-Ig activated B cells as well as its very early appearance were unexpected observations. We observed that IL-6 mRNA rapidly appears after anti-Ig activation of $B$ cells and peaks at $4 \mathrm{~h}$. Moreover, IL-2R mRNA also appears early and peaks at $8 \mathrm{~h}$. Both c-myc and IL-6 mRNA rapidly decrease ( 8 and $12 \mathrm{~h}$, respectively), whereas the IL-2R mRNA persists for at least $72 \mathrm{~h}$. Resting B cells do not express the c-myc proto-oncogene; however, c-myc is rapidly induced and its expression also peaks at $4 \mathrm{~h}$ (33). The observation that cycloheximide did not block IL-6 mRNA expression but instead led to increased levels suggested that IL-6 mRNA expression is one of the initial events of B cell activation, since induction of IL- 6 mRNA did not require protein synthesis. Previous in vitro studies with both Staphylococcus aureus protein $\mathrm{A}$ and anti-Ig have demonstrated that IL- 6 receptors are not detectable on resting $B$ cells and begin to be expressed on activated B cells after $24 \mathrm{~h}$ (34), before significant numbers of B cells begin to proliferate. Ig secretion is detectable by $96 \mathrm{~h}$, and with the addition of IL-6 increases progressively throughout $8 \mathrm{~d}$ of culture $(9,10)$. Although not precisely defined in the literature $(9,10)$, IL- 6 does not appear to be necessary during the first $4 \mathrm{~d}$ of culture but exerts its maximal differentiative effects later (4-8 d).

Synthesis of IL-6 mRNA suggests that activated B cells produce the IL- 6 protein, although we have yet to examine this. It seems most likely that B cell-derived IL- 6 might exert its effects on other cells within the microenvironment. B cells have been shown to be important in antigen presentation to $T$ cells; however, presentation of antigen in association with Ia alone is insufficient to activate T cells. Since IL-6 has previously been shown to function as a $\mathrm{T}$ cell activation factor (21), one of the most likely functions of B cell-derived IL-6 could be a role in T cell activation. B cell-derived IL- 6 , in conjunction with antigen presentation, could provide a complete activation stimulus for T lymphocytes. EBV-transformed $B$ cell lines that can function as accessory cells have been shown to produce an IL-1-like factor with the characteristics of IL-6 (35). An alternative function of B cell-derived IL-6 might be to induce and recruit previously activated B cells to differentiate into Ig-secreting cells. If the potential biologic effects of B cell-derived IL- 6 were on the B cell itself, then the early temporal appearance of IL- 6 mRNA would be difficult to explain, considering that the $B$ cell differentiative response to IL-6 is such a late event.

We also examined IL-6 mRNA expression in leukemias and lymphomas of B cell origin. Whereas 11 of 25 B cell NHLs and 4 of 4 myelomas expressed IL- 6 mRNA, only 1 of 19 B cell acute and chronic leukemias were positive. B cell NHLs are thought to correspond to the mid stages of B cell differentiation. For example, NPDLs are thought to correspond to B lymphocytes within the germinal center and DLCLs appear to be the neoplastic counterpart of proliferating blast B lymphocytes. In our series, all of the myelomas and PCLs corresponding to late stages of B cell differentiation, expressed IL-6 mRNA. In contrast, B cell acute leukemias (non-T ALL) that are derived from stages of pre-B cell differentiation or B cell chronic leukemias (CLL, HCL, and ProLL) did not appear to express detectable IL-6 mRNA.

In addition to its differentiative effects on B cells, IL-6 has been shown to be a growth factor for murine plasmacytomas, hybridomas, and EBV-infected human B lymphocytes. Recent evidence suggests that IL-6 may function as an autocrine factor. Kawano and his colleagues have demonstrated that IL-6 induces some human myelomas to proliferate, and more importantly, these myelomas appear to produce their own IL-6 (22). Few of the B cell tumor lines, including most of the myeloma cell lines, that we examined expressed IL-6 mRNA. Possibly in tumor cell lines a stage of autocrine dependence may be superceded by further oncogenic changes. In addition to autocrine effects, IL- 6 expression by a tumor may be responsible for systemic effects including fever, induction of acute phase proteins in the liver, and stimulation of hematopoiesis. Furthermore, secreted IL-6 might stimulate the proliferation of latently EBV-infected B cells.

In summary, we have observed that normal activated B cells and some neoplastic B cells express IL- 6 mRNA. The specific biologic role of B cell-derived IL- 6 is not currently known; however, this growth and differentiation factor appears to have a very wide array of functions. Its expression at an early stage of B cell activation and in more differentiated B cell tumors suggests a biologically important role for B cell-derived IL- 6 . We plan to examine the secretion of IL- 6 by normal and neoplastic B cells and its effects on cells of the microenvironment.

\section{Acknowledgments}

Probes for CD2. and CD14 were generously provided by Dr. David Simmons and Dr. Brian Seed. A probe for IL-6 was kindly provided by Dr. S. Clark and Dr. G. Wong (Genetics Institute). We gratefully acknowledge the assistance of Ms. Grace Wang in the preparation of this manuscript.

Dr. Freedman is supported by Public Health Services grant number 5K08 CA A01105-02 awarded by the National Cancer Institute, Department of Health and Human Services. This work is supported by National Institutes of Health grants CA-25369, CA-34183, and CA-40216. 


\section{References}

1. Taniguchi, T., H. Matsui, T. Fujita, C. Takaoka, N. Kashima, R. Yoshimoto, and J. Hamuro. 1983. Structure and expression of a cloned cDNA for human interleukin-2. Nature (Lond.). 32:305-310.

2. Yokota, T., T. Otsuka, T. Mosmann, J. Banchereau, T. DeFrance, D. Blanchard, J. De Vries, F. E. Lee, and K. I. Arai. 1986. Isolation and characterization of a human interleukin cDNA clone, homologous to mouse B-cell stimulatory factor 1, that expresses B-celland T-cell-stimulating activities. Proc. Natl. Acad. Sci. USA. 83:58945898.

3. Azuma, C., T. Tanabe, M. Konishi, T. Kinashi, T. Noma, F. Matsuda, Y. Yaoita, K. Takatsu, L. Hammarstrom, C. I. E. Smith, E. Severinson, and T. Honjo. 1986. Cloning of cDNA for human T-cell replacing factor (interleukin-5) and comparison with the murine homologue. Nucleic Acids Res. 14:9149-9158.

4. Hirano, T., K. Yasukawa, H. Harada, T. Taga, Y. Watanabe, T. Matsuda, S.-I. Kashiwamura, K. Nakajima, K. Koyama, A. Iwamstsu, S. Tsuarsawa, F. Sakiyama, H. Matsui, Y. Takahara, T. Taniguchi, and T. Kishimoto. 1986. Complementary DNA for a novel human interleukin (BSF-2) that induces B lymphocytes to produce immunoglobulin. Nature (Lond.). 324:73-76.

5. Sharma, S., S. Mehta, J. Morgan, and A. Maizel. 1987. Molecular cloning and expression of a human B-cell growth factor gene in Escherichia coli. Science (Wash. DC). 235:1489-1492.

6. Oliver K., R. J. Noelle, J. W. Uhr, P. H. Krammer, and E. S. Vitetta. 1985. B-cell growth factor (B-cell growth factor I or B-cellstimulating factor, provisional 1) is a differentiation factor for resting B cells and may not induce cell growth. Proc. Natl. Acad. Sci. USA. 82:2465-2467.

7. Waldmann, T. A., C. K. Goldman, R. J. Robb, J. M. Depper, W. J. Leonard, S. O. Sharrow, K. F. Bongiovanni, S. J. Korsmeyer, and W. C. Greene. 1984. Expression of interleukin 2 receptors on activated human B cells. J. Exp. Med. 160:1450-1466.

8. Snapper, C. M., and W. E. Paul. 1988. Interferon- $\gamma$ and B cell stimulatory factor-1 reciprocally regulate Ig isotype production. Science (Wash. DC). 236:944-947.

9. Muraguchi, A., T. Hirano, B. Tang, T. Matsuda, Y. Horii, K. Nakajima, and T. Kishimoto. 1988. The essential role of B cell stimulatory factor 2 (BSF-2/IL-6) for the terminal differentiation of B cells. J. Exp. Med. 167:332-344.

10. Hirano, T., T. Teranishi, and K. Onoue. 1984. Human helper T cell factor(s). III. Characterization of B cell differentiation factor I (BCDF-I). J. Immunol. 132:229-234.

11. Hirano, T., T. Taga, N. Nakano, K. Yasukawa, S. Kashiwamura, K. Shimizu, K. Nakajima, K. Pyun, and T. Kishimoto. 1985. Purification to homogeneity and characterization of human B-cell differentiation factor (BCDF or BSFp2). Proc. Natl. Acad. Sci. USA. 82:5490-5494.

12. Zilberstein, A., R. Ruggieri, J. H. Korn, and M. Revel. 1986. Structure and expression of cDNA and genes for human interferon- $\beta 2$, a distinct species inducible by growth-stimulatory cytokines. $E M B O$ (Eur. Mol. Biol. Organ.) J. 5:2529-2537.

13. Van Damme, J., G. Opdenakker, R. J. Simpson, M. R. Rubira, S. Cayphas, A. Vink, A. Billial, and J. Van Snick. 1987. Identification of the human $26-\mathrm{kD}$ protein, interferon $\beta 2$ (IFN- $\beta_{2}$ ) as a B cell hybridoma/plasmacytoma growth factor induced by interleukin I and tumor necrosis factor. J. Exp. Med. 165:914-919.

14. Aarden, L. A., E. R. De Groot, O. L. Schaap, and P. M. Lansdorp. 1987. Production of hybridoma growth factor by human monocytes. Eur. J. Immunol. 17:1411-1416.

15. Nordan, R. P., J. G. Pumphrey, and S. Rudikoff. 1987. Purification and $\mathrm{NH}_{2}$-terminal sequence of a plasmacytoma growth factor derived from the murine macrophage cell line P388D1. J. Immunol. 139:813-817.

16. Tosato, G., T. L. Gerrard, N. G. Goldman, and S. E. Pike. 1988. Stimulation of EBV-activated human B cells by monocytes and monocyte products: role of IFN- $\beta 2 /$ B cell stimulatory factor $2 / \mathrm{IL}-6 . J$. Immunol. 140:4329-4336.
17. Wong, G. G., J. S. Witek-Gianotti, P. A. Temple, R. Kriz, C. Ferenz, R. M. Hewick, S. C. Clark, K. Ikebuchi, and M. Ogawa. 1988. Stimulation of murine hemopoietic colony formation by human IL-6. J. Immunol. 140:3040-3044.

18. Takai, Y., G. G. Wong, S. C. Clark, S. J. Burakoff, and S. H. Herrmann. 1988. B cell stimulatory factor- 2 is involved in the differentiation of cytotoxic T lymphocytes. J. Immunol. 140:508-512.

19. Gauldie, J., C. Richards, D. Harnish, P. Lansdorp, and H. Baumann. 1987. Interferon $\beta 2 / \mathrm{B}$-cell stimulatory factor type 2 shares identity with monocyte-derived hepatocyte-stimulating factor and regulates the major acute phase protein response in liver cells. Proc. Natl. Acad. Sci. USA. 84:7251-7255.

20. Lotz, M., F. Jirik, P. Kabouridis, C. Tsoukas, T. Hirano, T. Kishimoto, and D. A. Carson. 1988. B cell stimulating factor 2/interleukin 6 is a costimulant for human thymocytes and T lymphocytes. $J$. Exp. Med. 167:1253-1258.

21. Garman, R. D., K. A. Jacobs, S. C. Clark, and D. H. Raulet. 1987. B-cell-stimulatory factor 2 ( $B_{2}$ interferon) functions as a second signal for interleukin 2 production by mature murine $\mathrm{T}$ cells. Proc. Natl. Acad. Sci. USA. 84:7629-7633.

22. Kawano, M., T. Hirano, T. Matsuda, T. Taga, Y. Horii, K. Iwato, H. Asaoku, B. Tang, O. Tanabe, H. Tanaka, A. Kuramoto, and T. Kishimoto. 1988. Autocrine generation and requirement of BSF-2/ IL-6 for human multiple myelomas. Nature (Lond.). 332:83-85.

23. Sporn, M. B., and A. B. Roberts. 1985. Autocrine growth factors and cancer. Nature (Lond.). 313:745-747.

24. Rappaport, H. 1966. Atlas of Tumor Pathology, section III, Fascicle 8. Armed Forces Institute of Pathology, Washington, DC.

25. Freedman, A. S., G. Freeman, J. C. Horowitz, J. Daley, and L. M. Nadler. 1987. B7, a B cell-restricted antigen that identifies preactivated B cells. J. Immunol. 139:3260-3267.

26. Chirgwin, J. M., A. E. Przybyla, R. J. MacDonald, and W. J. Rutter. 1979. Isolation of biologically active ribonucleic acid from sources enriched in ribonuclease. Biochemistry. 18:5294-5299.

27. Maniatis, T., E. F. Fritsch, and J. Sambrook. 1982. Molecular Cloning: A Laboratory Manual. Cold Spring Harbor Laboratory, Cold Spring Harbor, NY. 545 pp.

28. Vogelstein, B., and D. Gillespie. 1979. Preparative and analytical purification of DNA from agarose. Proc. Natl. Acad. Sci. USA. 76:615-619.

29. Feinberg, A. P., and B. Vogelstein. 1983. A technique for radiolabeling DNA restriction endonuclease fragments to high specific activity. Anal. Biochem. 132:6-13.

30. Okayama, H., and P. Berg. 1983. A cDNA cloning vector that permits expression of cDNA inserts in mammalian cells. Mol. Cell. Biol. 3:280-289.

31. Shipp, M. A., and E. L. Reinherz. 1987. Differential expression of nuclear proto-oncogenes in $\mathrm{T}$ cells triggered with mitogenic and nonmitogenic T3 and T11 activation signals. J. Immunol. 139:21432148.

32. Kvalheim, G., O. Sorensen, O. Fodstad, S. Funderud, S. Kiesel, B. Dorken, N. Nustad, E. Jakobsen, J. Ugelstad, and A. Pihl. 1988. Immunomagnetic removal of B-lymphoma cells from human bone marrow: a procedure for clinical use. Bone Marrow Transplant. 3:31-41.

33. Klinman, D. M., J. F. Mushinski, M. Honda, Y. Ishigatsubo, J. D. Mountz, E. S. Raveche, and A. D. Steinberg. 1986. Oncogene expression in autoimmune and normal peripheral blood mononuclear cells. J. Exp. Med. 163:1292-1307.

34. Taga, T., Y. Kawanishi, R. R. Hardy, T. Hirano, and T. Kishimoto. 1987. Receptors for B cell stimulatory factor 2: quantitation, specificity, distribution, and regulation of their expression. J. Exp. Med. 166:967-981.

35. Matsushima, K., Y.-D. Kuang, G. Tosato, S. J. Hopkins, and J. J. Oppenheim. 1985. B-cell derived interleukin 1 (IL-1)-like factor. I. Relationship of production of IL-1-like factor to accesory cell function of Epstein-Barr virus-transformed human B-lymphoblast lines. Cell. Immunol. 94:406-417. 